\title{
Research on Fiscal Sustainability Risk Evaluation Model Based on Large-Scale Regional Comprehensive Development PPP Project
}

\author{
Li Xianhao, ${ }^{1, a}$, Wang Yue ${ }^{2, b}$, Wang Lin*c \\ ${ }^{1}$ School of Management Science and Real Estate, Chongqing University No.83, Chongqing University, Sha Pingba District, Chongqing \\ City。Zip code 400044。Email address: limoster@126.com \\ ${ }^{2}$ Business School, Sichuan University, Wangjiang Campus, Sichuan University, Wuhou District, Zip code 610000。Email address: \\ 18200226919@163.com \\ *School of Management Science and Real Estate, Chongqing University。Zip code 400044。Email address: wangidill@163.com
}

\begin{abstract}
With the development of urbanization in China, the traditional PPP mode is no longer suitable for the urbanization in China. Therefore, the regional comprehensive development PPP mode is gradually concerned by government and enterprises. In view of the above development trend, this paper establishes a model of fiscal sustainability risk for large-scale regional comprehensive development PPP project to realize efficient allocation of resources, value maximization, fiscal sustainability risk evaluation, so as to achieve fiscal sustainability.
\end{abstract}

\section{Research Background}

After years of practice, many problems of traditional single PPP mode have been found, such as obscuring equity and debt, governmental implicit debt risks without long term payment mechanism, shortage of user charges or new income, which make it less acceptable by both public sectors and enterprises.

The regional comprehensive development PPP mode has become a good way to solve those problems. It is a new PPP mode to develop certain region, improve regional value and enhance self-development ability. The large-scale regional comprehensive development PPP mode has the characteristics of wide development area, large investment, many partners involved and long cooperation cycle, so the requirements for public sectors and enterprises are higher, and the fiscal sustainability risk is also higher.

\section{Fiscal Sustainability Risk Evaluation Model}

With the increasing experience in developing large-scale regional comprehensive development PPP projects, the risks are gradually appeared, such as the uncertainty brought by long-term contracts under the PPP mode, the realization and improvement of performance, the matching of project investment budget and government financial budget. The reliability of government revenue and other issues also increase the fiscal sustainability risk. In this paper, we propose a fiscal sustainability risk evaluation model under PPP mode of large-scale regional comprehensive development, so as to help to better achieve comprehensive fiscal balance.

\subsection{Evaluation of Fiscal Sustainability risk}

Combined with the practical experience of large-scale regional comprehensive development PPP project, this paper decomposes the fiscal sustainability risks under the promotion of large-scale regional comprehensive development PPP project into the following categories.

\subsubsection{Subproject management risk}

Comprehensive development projects often involve multiple subprojects, and the construction of each subproject may not be started at the same time. In general, the financial feasibility and investment budget of overall PPP project are calculated before implementation. However, the investment and financing plan of subprojects are not clearly agreed because subprojects are constructed stage-by-stage and rolling-investment. The actual situation of each subproject may cause great deviation with overall plan, which will have a great impact on the project financial balance and PPP contract implementation, reduce the decision-making effect of investment budget.

\subsubsection{Land management risk}

Most of land reservation, expropriation and relocation programs are in the charge of by public sectors, and the 
enterprise and SPV are rarely involved in. The separation of administrative functions, such as land use, acquisition and transfer reduce the operability of the project, as well as the effectiveness of the operation performance evaluation mechanism and the internal incentive mechanism of the SPV. On the one hand, land acquisition and transfer are greatly affected by the administrative approval of the government and relevant departments. On the other hand, the calculation of land transfer income in the project implementation plan is based on the overall plan and whole life cycle of the project, but in fact, the land transfer plan is difficult to effectively cover the whole project period, thus affecting the financial risk assessment of the project.

\subsubsection{Risk of finance ability}

The promotion of the value of the cooperation area is a major source of return for regional comprehensive development PPP projects, which brings a large amount of urban operation revenue and government finance revenue so as to occupy less stock financial resources and reduce the financial risk of the government. However, this return mechanism has certain impact on the project finance ability because it is difficult to reasonably predict the future industrial development and guarantee the government financial revenue. In additional, the value of public service facilities of SPV cannot be realized and is difficult to circulate, PPP projects are difficult to finance by itself, external credit guarantee is often needed, such as government credit, enterprise credit or guarantee, etc.

\subsubsection{Risk of cash flow fluctuation in the whole life cycle}

Most of the large-scale regional comprehensive development PPP projects are operated with government subsidies to guarantee its return. The accuracy of financial budget is not as high as that of other traditional single PPP projects. In the meanwhile, there are many subprojects of large-scale regional comprehensive development PPP projects, and the stability of cash flow of each subproject is quite different. The fluctuations of user payment of some public facilities are relatively small due to its stability of public consumption, while the fluctuation of land transfer income and Industry income is relatively large, which is greatly affected by external conditions such as macro-economy and policy orientation. All of these factors make the life cycle cash flow fluctuates greatly and improves the financial sustainability risk.

\subsection{Construction of Fiscal Sustainability Risk Evaluation Model}

Based on the above analysis and discussion, this paper constructs the fiscal sustainability risk evaluation model for large-scale regional comprehensive development PPP project with the help of analytic hierarchy process(AHP). On this basis, expert opinions are collected to conduct qualitative and quantitative analysis, find out the risks need to be prevented, and finally put forward countermeasures and improvement suggestions.

\subsubsection{Hierarchy building}

Based on the above analysis of fiscal sustainability risk factors of large-scale regional comprehensive development PPP project, the risk situation is sorted as the following hierarchy chart, as shown in table 1.

Table 1 Indexes of fiscal sustainability risk of large-scale regional comprehensive development PPP projects

\begin{tabular}{|c|c|c|}
\hline \multirow{2}{*}{ Target Level } & \multicolumn{2}{|r|}{ Risk Factors } \\
\hline & Primary Indexes & Secondary Indexes \\
\hline \multirow{11}{*}{$\begin{array}{c}\text { Fiscal sustainability } \\
\text { risk of large-scale } \\
\text { regional } \\
\text { comprehensive } \\
\text { development PPP } \\
\text { project (A) }\end{array}$} & \multirow{5}{*}{$\begin{array}{l}\text { Subproject } \\
\text { management } \\
\text { risk }\left(B_{1}\right)\end{array}$} & Subproject investment and finance plan $\left(\mathrm{C}_{11}\right)$ \\
\hline & & Subproject construction progress $\left(\mathrm{C}_{12}\right)$ \\
\hline & & Subproject investment cost $\left(\mathrm{C}_{13}\right)$ \\
\hline & & Subproject operating revenue $\left(\mathrm{C}_{14}\right)$ \\
\hline & & Subproject tax revenue $\left(\mathrm{C}_{15}\right)$ \\
\hline & \multirow{5}{*}{$\begin{array}{l}\text { Land } \\
\text { management } \\
\operatorname{risk}\left(B_{2}\right)\end{array}$} & Land reserve program $\left(\mathrm{C}_{21}\right)$ \\
\hline & & Land expropriation relocation program $\left(\mathrm{C}_{22}\right)$ \\
\hline & & Construction land quota $\left(\mathrm{C}_{23}\right)$ \\
\hline & & Land grant $\left(\mathrm{C}_{24}\right)$ \\
\hline & & Administrative approval $\left(\mathrm{C}_{25}\right)$ \\
\hline & & Land transfer income $\left(\mathrm{C}_{31}\right)$ \\
\hline
\end{tabular}




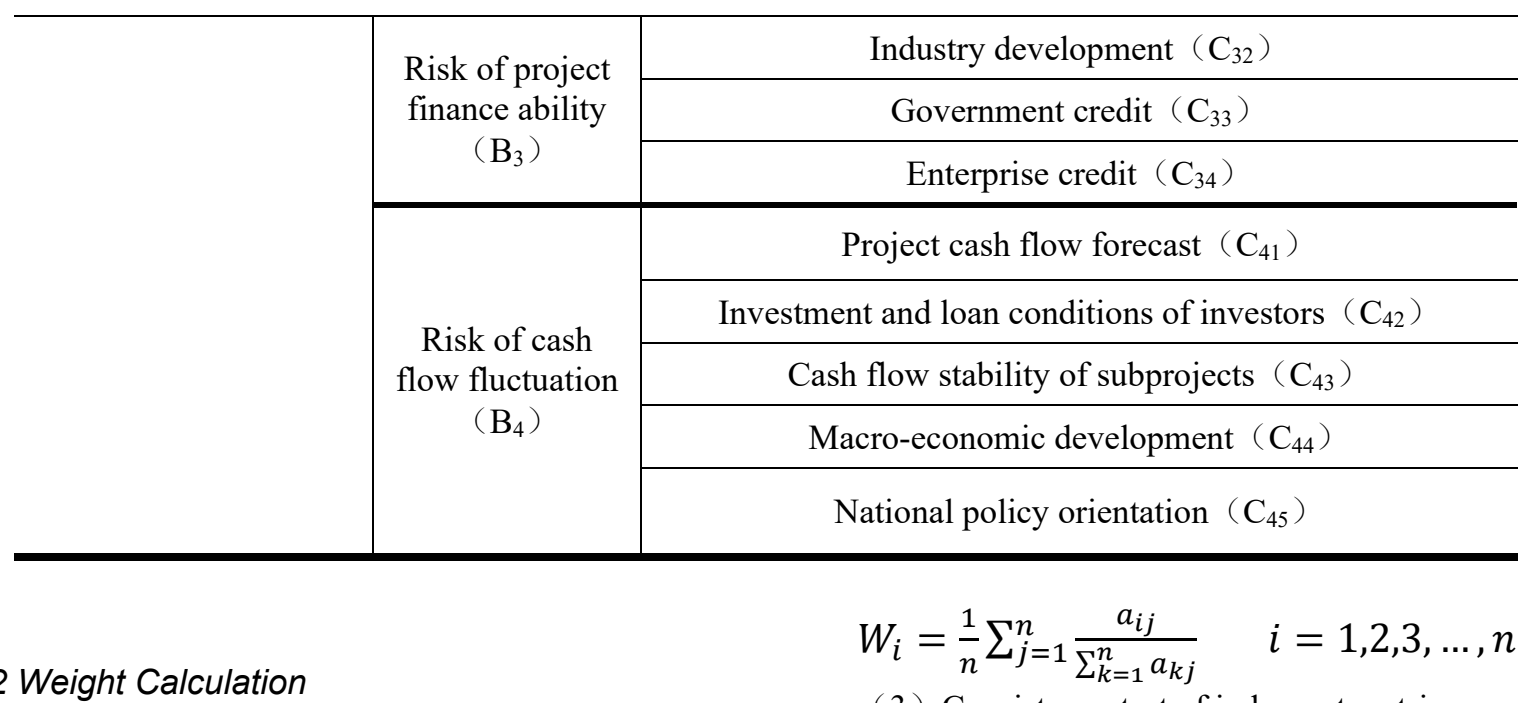

\subsubsection{Weight Calculation}

(1) Establishment pairwise comparison judgment matrix

In order to reduce the influence of subjective judgement, the pairwise comparison judgment matrix is established to compare relative importance of each index (C) in the same index level (B). Generally speaking, the indexes of target level dominant indexes of stadard level Bi. Therefore, a comparison judgment matrix of Bi based on A can be established.

In the analytic hierarchy process(AHP), we make statistics of expert opinions to form the above-mentioned numerical judgment matrix, so as to make quantitative judgment. A. L. Saaty 1-9 scale method is used to determine the relative importance of the matrix.

(2) Calculation the weight values of indexes in each level

There are mainly 2 methods to calculate the weight values of the comparative judgment matrix, summation method is used in this paper:
(3) Consistency test of judgment matrix

After calculating the weight vector through the above steps, it is necessary to check the consistency of each judgment matrix, when the judgment matrix meets:

$$
C . R=\frac{C . I}{R . I}<0.1
$$

the consistency of the judgment matrix is acceptable.

Among them, C.I is the consistency index:

$$
C . I=\frac{\left(\lambda_{\max }-n\right)}{n}
$$

$\lambda_{\max }$ is the maximum eigenvalue of matrix:

$$
\lambda_{\max }=\sum_{i=1}^{n} \frac{(A w)_{i}}{n w_{i}}
$$

$(A w)_{i}$ is the ith element of vector Aw.

R.I(Random Index) is the average random consistent index, it can be looked up in Table 2:

Table 2 Matrix Order and Corresponding Average Random Consistent Index

\begin{tabular}{ccccccccccc}
\hline Matrix order & 1 & 2 & 3 & 4 & 5 & 6 & 7 & 8 & 9 & 10 \\
\hline R.I & 0 & 0 & 0.52 & 0.89 & 1.12 & 1.26 & 1.36 & 1.41 & 1.46 & 1.49 \\
\hline
\end{tabular}

\subsubsection{Factor Evaluation Index System}

(1) First-level fuzzy comprehensive evaluation

The system is divided according to the impact degree of the listed factors on the income and risk of infrastructure projects, and the impact degree can be divided into five levels, which are very small $(0.1)$, small (0.3), general (0.5), large (0.7), very large (0.9).

Evaluation level $\mathrm{Y}=$ (very small, small, general, large, very large ) 。

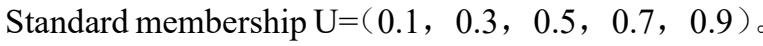

Then the experts evaluate each factor according to the evaluation level, and get the first level fuzzy comprehensive evaluation matrix:

$$
R=\left[\begin{array}{cccc}
r_{11} & r_{12} & \cdots & r_{1 m} \\
r_{21} & r_{22} & \cdots & r_{2 m} \\
\vdots & \vdots & \vdots & \vdots \\
r_{n 1} & r_{n 2} & \cdots & r_{n m}
\end{array}\right] \quad \text { (5) }
$$

(2) Second-level fuzzy comprehensive evaluation

The second level fuzzy comprehensive evaluation is to evaluate all factors of the factor subset through the formula $\mathrm{Bi}=\mathrm{Ai} \times \mathrm{Ri}$. In this way, evaluation grade of each factor in the criterion level can be calculated.

(3) Third-level fuzzy comprehensive evaluation

The third level fuzzy comprehensive evaluation is to comprehensive evaluation through the formula $\mathrm{B}=\mathrm{A} \times \mathrm{Bi}$, then comprehensive membership of $\mathrm{A}$ is calculated as 
$\mathrm{P}=\mathrm{B} \times \mathrm{UT}$, compared with evaluation level $\mathrm{Y}$, the overall risk level of project A can be assessed.

\section{Research Application in Practical Cases}

\subsection{Case background}

This paper takes a large-scale regional comprehensive development PPP project in China as an example. The project adopts the "BOT" (Build-Operate-Transfer) PPP mode to develop an economic development zone. Return of the project is the new financial revenue of regional development. Most of risks mentioned above can be reflected in this project. This paper will apply the fiscal sustainability risk evaluation model into this project to enhance the effectiveness of research results.

\subsection{Project Fiscal Sustainability risk analysis}

We invite 20 experts from fields of management, engineering technology, finance, asset evaluation, industry, law, accounting, etc. to evaluate and grade every risk index after fully understanding the project situation.

\subsubsection{Hierarchy analysis}

Objected weight: According to the analytic hierarchy process(AHP), we analyze the questionnaire survey results about the risk factors affecting the project of experts, results shown as Table 3:

Table 3 Judgement Matrix of Risk Factors

\begin{tabular}{clllll}
\hline $\mathrm{A}$ & $\mathrm{B}_{1}$ & $\mathrm{~B}_{2}$ & $\mathrm{~B}_{3}$ & $\mathrm{~B}_{4}$ & $\mathrm{~W}$ \\
\hline $\mathrm{B}_{1}$ & 1 & $1 / 5$ & $1 / 3$ & 2 & 0.114 \\
$\mathrm{~B}_{2}$ & 5 & 1 & $1 / 2$ & 4 & 0.336 \\
$\mathrm{~B}_{3}$ & 3 & 2 & 1 & 7 & 0.481 \\
$\mathrm{~B}_{4}$ & $1 / 2$ & $1 / 4$ & $1 / 7$ & 1 & 0.069 \\
\hline Result & & $\lambda_{\max }=4.148$ & $\mathrm{CI}=0.049 \quad \mathrm{CR}=0.055$ & \\
\hline
\end{tabular}

$\mathrm{CR}=0.049 / 0.89=0.055<0.1$, which means the consistency is qualified and the level division is reasonable. In the same way, weight, eigenvalues $\left(\lambda_{\max }\right), \mathrm{CI}$ and CR are calculated, results shown as Table 4 to 6 :

Table 4 Subproject Management Risk

\begin{tabular}{ccccccc}
\hline $\mathrm{B}$ & $\mathrm{C}_{11}$ & $\mathrm{C}_{12}$ & $\mathrm{C}_{13}$ & $\mathrm{C}_{14}$ & $\mathrm{C}_{15}$ & $\mathrm{~W}$ \\
\hline $\mathrm{C}_{11}$ & 1 & $1 / 5$ & $1 / 3$ & $1 / 9$ & $1 / 7$ & 0.033 \\
$\mathrm{C}_{12}$ & 5 & 1 & 3 & $1 / 5$ & $1 / 3$ & 0.130 \\
$\mathrm{C}_{13}$ & 3 & $1 / 3$ & 1 & $1 / 7$ & $1 / 5$ & 0.064 \\
$\mathrm{C}_{14}$ & 9 & 5 & 7 & 1 & 3 & 0.510 \\
$\mathrm{C}_{15}$ & 7 & 3 & 5 & $1 / 3$ & 1 & 0.264 \\
\hline Result & \multicolumn{8}{c}{$\lambda_{\max }=5.237$} & $\mathrm{CI}=0.059$ & $\mathrm{CR}=0.053$ & \\
\hline
\end{tabular}

Table 5 Land Management Risk

\begin{tabular}{ccccccc}
\hline $\mathrm{A}$ & $\mathrm{C}_{21}$ & $\mathrm{C}_{22}$ & $\mathrm{C}_{23}$ & $\mathrm{C}_{24}$ & $\mathrm{C}_{25}$ & $\mathrm{~W}$ \\
\hline $\mathrm{C}_{21}$ & 1 & $1 / 6$ & $1 / 3$ & $1 / 9$ & $1 / 7$ & 0.032 \\
$\mathrm{C}_{22}$ & 6 & 1 & 2 & $1 / 5$ & $1 / 3$ & 0.124 \\
$\mathrm{C}_{23}$ & 3 & $1 / 2$ & 1 & $1 / 7$ & $1 / 5$ & 0.069 \\
$\mathrm{C}_{24}$ & 9 & 5 & 7 & 1 & 3 & 0.511 \\
$\mathrm{C}_{25}$ & 7 & 3 & 5 & $1 / 3$ & 1 & 0.264 \\
\hline Result & \multicolumn{7}{c}{$\lambda_{\max }=5.221 \quad \mathrm{CI}=0.055$} & $\mathrm{CR}=0.049$ & \\
\hline
\end{tabular}

Table 6 Risk of Project Finance Ability

\begin{tabular}{cccccc}
\hline $\mathrm{A}$ & $\mathrm{C}_{31}$ & $\mathrm{C}_{32}$ & $\mathrm{C}_{33}$ & $\mathrm{C}_{33}$ & $\mathrm{~W}$ \\
\hline $\mathrm{C}_{31}$ & 1 & $1 / 4$ & $1 / 3$ & 2 & 0.125 \\
$\mathrm{C}_{32}$ & 4 & 1 & 2 & 4 & 0.464 \\
$\mathrm{C}_{33}$ & 3 & $1 / 2$ & 1 & 6 & 0.338 \\
$\mathrm{C}_{33}$ & $1 / 2$ & $1 / 4$ & $1 / 6$ & 1 & 0.074 \\
\hline Result & \multicolumn{7}{c}{$\lambda_{\max }=4.117 \quad \mathrm{CI}=0.039 \mathrm{CR}=0.044$} \\
\hline
\end{tabular}


Table 7 Risk of Cash Flow Fluctuation

\begin{tabular}{ccccccc}
\hline $\mathrm{A}$ & $\mathrm{C}_{41}$ & $\mathrm{C}_{42}$ & $\mathrm{C}_{43}$ & $\mathrm{C}_{44}$ & $\mathrm{C}_{45}$ & $\mathrm{~W}$ \\
\hline $\mathrm{C}_{41}$ & 1 & $1 / 8$ & $1 / 3$ & $1 / 9$ & $1 / 8$ & 0.029 \\
$\mathrm{C}_{42}$ & 8 & 1 & 2 & $1 / 4$ & $1 / 3$ & 0.138 \\
$\mathrm{C}_{43}$ & 3 & $1 / 2$ & 1 & $1 / 7$ & $1 / 5$ & 0.069 \\
$\mathrm{C}_{44}$ & 9 & 4 & 7 & 1 & 3 & 0.491 \\
$\mathrm{C}_{45}$ & 8 & 3 & 5 & $1 / 3$ & 1 & 0.273 \\
\hline Result & \multicolumn{7}{c}{$\lambda_{\max }=5.256 \quad \mathrm{CI}=0.064 \mathrm{CR}=0.057$} & \\
\hline
\end{tabular}

\subsubsection{Factor Evaluation}

(1) First-level fuzzy comprehensive evaluation

\begin{tabular}{|c|c|c|c|c|c|c|c|c|c|c|c|}
\hline \multirow{5}{*}{$R_{1}=$} & 0 & 0.4 & 0.5 & 0.1 & 0 & \multirow{5}{*}{$R_{2}=$} & -0.1 & 0 & 0.5 & 0.2 & 0.2 \\
\hline & 0.25 & 0.5 & 0.25 & 0 & \multirow{2}{*}{0} & & \multirow{2}{*}{$\begin{array}{c}0.25 \\
0\end{array}$} & 0.1 & 0 & 0 & 0.65 \\
\hline & 0 & 0.25 & 0.25 & 0.5 & & & & 0.3 & 0 & 0.5 & 0.2 \\
\hline & 0 & 0 & 0.25 & 0.35 & 0.4 & & 0.15 & 0.5 & 0 & 0.35 & 0 \\
\hline & 0 & 0.25 & 0.35 & 0.4 & 0 & & -0.4 & 0.3 & 0.1 & 0 & 0.2 \\
\hline & {$[0.2$} & 0 & 0.25 & 0.3 & $0.2]$ & & & 0.1 & 0.25 & 0.4 & 0.25 \\
\hline & 0.3 & 0.1 & 0.3 & 0.3 & 0 & & 0.4 & 0.3 & 0.3 & 0 & 0 \\
\hline$R_{2}=$ & 0.15 & 0.15 & 0.1 & 0.3 & 0.3 & $R_{4}=$ & 0.4 & 0.4 & 0.2 & 0 & 0 \\
\hline & $L_{0.25}$ & 0.4 & 0.15 & 0.2 & 0 & & 0.1 & $\begin{array}{l}0.3 \\
01\end{array}$ & $\begin{array}{l}0.4 \\
0.3\end{array}$ & 0.2 & 0 \\
\hline
\end{tabular}

(2) Second-level fuzzy comprehensive evaluation

$\boldsymbol{B}_{1}=(0.0324,0.1598,0.2846,0.3192,0.2040)$

$\boldsymbol{B}_{2}=(0.2165,0.3678,0.0423,0.2197,0.1537)$

$\boldsymbol{B}_{3}=(0.2394,0.1266,0.2151,0.2926,0.1262)$

$\boldsymbol{B}_{\mathbf{4}}=(0.0293,0.1381,0.0694,0.4906,0.2726)$

(3) Third-level fuzzy comprehensive evaluation

$$
\boldsymbol{B}=(0.1141,0.3359,0.4809,0.0691)\left[\begin{array}{lllll}
0.0324 & 0.1598 & 0.2846 & 0.3192 & 0.2040 \\
0.2165 & 0.3678 & 0.0423 & 0.2197 & 0.1537 \\
0.2394 & 0.1266 & 0.2151 & 0.2926 & 0.1262 \\
0.0293 & 0.1381 & 0.0694 & 0.4906 & 0.2726
\end{array}\right]
$$

$P=(0.0708,0.1028,0.1008,0.1199,0.0623)\left[\begin{array}{c}0.1 \\ 0.3 \\ 0.5 \\ 0.7 \\ 0.9\end{array}\right]=0.2283$

(4) Results Analysis

According to the above calculation, the comprehensive risk membership of the project is 0.2283 , with relative low risk and good compliance.

It can be found that the maximum risk faced by the project is finance risk through the analytic hierarchy process. This is because the return of the project depends on promotion of regional value and incremental reward, so the urban operation revenue and the new financial revenue in the region are very important. The new financial revenue depends on the future long-term economic development and political orientation rather than the visible stock fiscal revenue. It is clearly that this project has greater uncertainty for the bank and investment institution, and finance countered much more risk.

The second major risk is land management risk, which is because the enterprise can not participate in the work of land collection, storage and transfer in the project, but its repayment source is highly dependent on the income of land management. In additional, the project cycle is quite long and involves a wide range of land, so the uncertainty of land acquisition cost and land transfer is quite high.

\section{Summary}

(1) Match the project investment budget with the government fiscal budget, and enhance the prediction and control of cash flow

As for large-scale regional comprehensive development PPP projects, it is necessary to make a realtime tracking of cash flow and financial expenditure corresponding to the project progress, timely adjust investment budget of each subproject, then embed it into the medium-term fiscal plan, so as to have a clearer estimation of investment schedule of many subprojects in 
the whole life cycle. In additional, the expenditure quota control of the medium-term financial plan to the project budget and the fiscal year budget is an important link to effectively control the fiscal sustainable development.

(2) Promote project operation stability and fiscal sustainability through intertemporal budget-balance mechanism

The goal of intertemporal budget-balance mechanism is consistent with the goal of promoting project operation stability and fiscal sustainability. The medium-term fiscal plans lay a solid foundation for intertemporal budget balance. In additional, with the implementation of ultra short revenue expenditure balance mechanism and debt risk control mechanism, intertemporal budget balance can be achieved and stability of project operation and fiscal sustainability can be promoted.

(3) Enhance project finance ability

As for PPP projects, brought into PPP information platform of China Public Private Partnerships Center, monitored by annual government budget, implemented the medium-term finance planning would play an important role of enhancement the project finance ability. With the improvement of the medium-term financial planning management, its binding force and legal status will be further enhanced, and the project's finance ability will be further enhanced.

\section{Reference}

1. Al-Saadi R, Abdou A. Factors critical for the success of public-private partnerships in UAE infrastructure projects: experts' perception[J]. International Journal of Construction Management, 2016, 16(3): 234-248.

2. Ameyaw E E, Chan A P C. A fuzzy approach for the allocation of risks in public-private partnership water-infrastructure projects in developing countries[J]. Journal of Infrastructure Systems, 2016, 22(3): 04016016.

3. Bing L, Akintoye A, Edwards P J, et al. The allocation of risk in PPP/PFI construction projects in the UK[J]. International Journal of project management, 2005, 23(1): 25-35

4. Carbonara N, Pellegrino R, Vajdic N. Real option theory for risk mitigation in transport PPPs[J]. Built Environment Project and Asset Management, 2013.

5. Dikmen I, Birgonul M T, Han S. Using fuzzy risk assessment to rate cost overrun risk in international construction projects $[\mathrm{J}]$. International Journal of Project Management, 2007, 25(5): 494-505.

6. Effah Ameyaw E, Chan A P C. Identifying publicprivate partnership (PPP) risks in managing water supply projects in Ghana[J]. Journal of Facilities Management, 2013, 11(2): 152-182.

7. Hwang B G, Zhao X, Gay M J S. Public private partnership projects in Singapore: Factors, critical risks and preferred risk allocation from the perspective of contractors[J]. International Journal of Project Management, 2013, 31(3): 424-433.
8. Iyer K C, Sagheer M. Hierarchical structuring of PPP risks using interpretative structural modeling[J]. Journal of Construction Engineering and Management, 2009, 136(2): 151-159. 